\title{
Changes in Clinical Measures and Tissue Adaptations in Collegiate Swimmers Across a Competitive Season
}

Ryan Paul ${ }^{1}$, Angela Tate, PT, $\mathrm{PhD}^{2}$, Joseph Sarver, $\mathrm{PhD}^{3}$, Laura DiPaola, SPT 2 , Jeffery Yi, SPT ${ }^{2}$, Stephen Thomas, PhD, ATC 1

${ }^{1}$ Department of Kinesiology, College of Public Health, Temple University

${ }^{2}$ Department of Physical Therapy, Arcadia University

${ }^{3}$ Department of Bioengineering, Drexel University

Correspondence: sjthomasatc@,temple.edu (Stephen Thomas, PhD, ATC)

\section{Background}

According to the NCAA Sports Sponsorship and Participations Rates Report, 22,375 male and female collegiate swimmers competed during the 2016-2017 season. ${ }^{1}$ Despite their competitive success, $29.5 \%$ of recently surveyed NCAA swimmers reported competing with arm trouble along with $18.2 \%$ competing with a current injury. ${ }^{2}$ The same authors also suggest a cumulative effect of swimming training on shoulder pain as shown by swimmers competing 11 or more years having lower functional scores than swimmers competing 10 years or less. ${ }^{2}$ The large population of collegiate swimmers, prevalence of shoulder pain, and reduced shoulder function with increased training warrants further investigation.

Due to high training volume, competitive swimmers incur shoulder pain and injury, ${ }^{1}$ but certain physical characteristics, such as shoulder range of motion (ROM) and endurance, and tissue adaptations such as posterior capsule thickness (PCT) and supraspinatus tendon structure may also be risk factors. Decreased endurance and ROM have been found in competitive swimmers along with being related to pain. ${ }^{3}$ However, no longitudinal studies have examined pain and disability, range of motion, training volume, shoulder endurance and tendon structure over the course of a competitive season.

\section{Purpose}

The purpose of this study was to: 1) to assess shoulder pain and disability, internal rotation (IR) and external rotation (ER) and horizontal adduction (HADD) ROM, and posterior shoulder endurance longitudinally over a competitive collegiate season, and 2) determine if there is a relationship between swimming yardage and supraspinatus tendon organization. 


\section{Methods}

Collegiate swimmers 18 years or older from a Division III university volunteered for participation in this study. Approval was granted by the university's Institutional Review Board. 17 male and 13 female Division III swimmers aged $19.6 \pm 1.1$ years participated, with training volume, swimming experience, and prevalence of shoulder pain available in Table 1.

\begin{tabular}{lccc}
\hline \multicolumn{1}{l}{ Table 1. Demographics of participants } & & \\
\hline \multicolumn{1}{c}{ Variables } & Male & Female & Combined \\
\hline Participants, n & 17 & 13 & 30 \\
Age, years & $19.8 \pm 1.1$ & $19.4 \pm 1.0$ & $19.6 \pm 1.1$ \\
Hours/week swimming & $14.9 \pm 6.1$ & $15.3 \pm 3.9$ & $15.1 \pm 5.2$ \\
Months/year swimming & $7.9 \pm 2.1$ & $9.7 \pm 2.2$ & $8.7 \pm 2.3$ \\
Years competitive swimming experience & $9.9 \pm 3.7$ & $12.7 \pm 2.3$ & $11.1 \pm 3.4$ \\
Previous should pain, \% & 58.8 & 69.2 & 63.3
\end{tabular}

A repeated measures design was used at 3 testing sessions during the competitive season: the beginning (T1), middle (T2), and end (T3). Pain and disability were assessed using the Penn Shoulder Score (ranges 0 to 40, with 40 indicating no pain) and the Disability of Arm Shoulder Hand sports module (ranges 4 to 20, with 4 indicating no difficulty in sport) as validated by previous research. ${ }^{45}$ Internal rotation (IR), external rotation (ER), and horizontal adduction (HA) were measured using a digital inclinometer. Shoulder endurance was measured using the Posterior Shoulder Endurance Test (PSET). Anterior, center, and posterior supraspinatus tendon images were collected by locating the anterior aspect of the tendon insertion and moving posteriorly. The ultrasound images were analyzed using custom MATlab software to quantify tissue organization.

Repeated measure ANOVAs were used to compare longitudinal changes across time. If $\mathrm{p}$-values were found to be $\leq 0.05$, follow-up paired t-tests with Bonferroni corrections were used to compare T1, T2, and T3. This protocol was IRB-approved and participants signed a written consent form.

\section{Results}

No significant changes in pain were observed, while disability did significantly decrease from T1 to T3 (Table 2).

An increase in swimming yardage from T1 to T2 was followed by a significant decrease in yardage to finish the swimming season (Table 3). Posterior shoulder endurance increased throughout the season (Table 3). IR and HA ROM decreased significantly between all timepoint comparisons (Table 3). 
Table 2.

Pain and disability rating at beginning (T1), middle (T2) and near end (T3) of competitive collegiate swimming season

\begin{tabular}{|c|c|c|c|c|}
\hline Variable & T1 & T2 & T3 & $P$ values \\
\hline PENN shoulder scoret & $31.2 \pm 6.0$ & $32.5 \pm 6.5$ & $32.3 \pm 6.0$ & $\begin{array}{l}0.1 \\
0.6 \\
0.2\end{array}$ \\
\hline DASH sports module $\neq$ & $6.83 \pm 3.2$ & $5.9 \pm 2.8$ & $5.16 \pm 2.7^{C}$ & $\begin{array}{c}0.2 \\
0.2 \\
.003 \mathrm{C}\end{array}$ \\
\hline $\begin{array}{l}\% \text { of swimmers with pain at rest } \mathrm{t}^{\mathrm{b}} \\
(\text { mean pain rating } \pm \mathrm{SD})\end{array}$ & $\begin{array}{c}36.7 \\
0.6 \pm 1.2\end{array}$ & $\begin{array}{c}24.1 \\
0.7 \pm 1.4\end{array}$ & $\begin{array}{c}22.2 \\
0.5 \pm 1.1\end{array}$ & \\
\hline $\begin{array}{l}\% \text { of swimmers with } \\
\text { Pain with normal } \\
\text { activities } \\
\text { (mean pain rating } \pm S D \text { ) }\end{array}$ & $1.4 \pm 1.7$ & $1.1 \pm 1.6$ & $1.2 \pm 1.6$ & \\
\hline $\begin{array}{l}\% \text { of swimmers with } \\
\text { Pain with strenuous } \\
\text { activities }^{\mathrm{b}} \\
\text { (mean pain rating } \pm \mathrm{SD} \text { ) }\end{array}$ & $4.1 \pm 2.3$ & $3.1 \pm 2.3$ & $3.4 \pm 2.1$ & \\
\hline
\end{tabular}

aSignificant change between T1 and T3 $(\mathrm{P}<.05)$

bPain level $\geq 1 / 10$

tPENN: Penn Shoulder Score (pain \& satisfaction subscales). Scores range from 0 to 40, with 40 indicating no pain and hihgh satisfaction of shoulder function.

‡DASH: Disabilities of the Arm, Shoulder, and Hand sports module. Scores range from 4 to 20, with 4 indicating no difficulty performing sport. 
Table 3.

Swimming yardage, ROM, Posterior Shoulder Endurance Test (PSET) at beginning (T1), middle (T2), and near end (T3) of competitive collegiate swimming season

\begin{tabular}{|c|c|c|c|c|}
\hline Variable & T1 & $\mathrm{T} 2$ & T3 & $P$ values \\
\hline \multicolumn{5}{|l|}{ External rotation $\left(^{\circ}\right)$} \\
\hline \multirow[t]{3}{*}{ Left } & $83 \pm 12$ & $92 \pm 13^{a}$ & $91 \pm 10^{c}$ & $.014^{a}$ \\
\hline & & & & 0.9 \\
\hline & & & & $.005^{\mathrm{c}}$ \\
\hline Right & $98 \pm 12$ & $96 \pm 14$ & $98 \pm 11$ & 0.7 \\
\hline \multicolumn{5}{|c|}{ Internal rotation $\left(^{\circ}\right)$} \\
\hline \multirow[t]{3}{*}{ Left } & $44 \pm 12$ & $36 \pm 11$ & $28 \pm 8^{\mathrm{b}, \mathrm{c}}$ & .035 \\
\hline & & & & $.004^{\mathrm{b}}$ \\
\hline & & & & $.0001^{\mathrm{c}}$ \\
\hline \multirow[t]{3}{*}{ Right } & $36 \pm 11$ & $29 \pm 9 a$ & $23 \pm 10^{b, c}$ & $.0001^{\mathrm{a}}$ \\
\hline & & & & $.009 \mathrm{~b}$ \\
\hline & & & & $.0001^{\mathrm{c}}$ \\
\hline \multicolumn{5}{|c|}{ Horizontal Adduction $\left({ }^{\circ}\right)$} \\
\hline \multirow[t]{3}{*}{ Left } & $87 \pm 10$ & $79 \pm 9 a$ & $74 \pm 8^{b, c}$ & $.0001^{\mathrm{a}}$ \\
\hline & & & & $.011^{\mathrm{b}}$ \\
\hline & & & & $.0001^{\mathrm{c}}$ \\
\hline \multirow[t]{2}{*}{ Right } & $84 \pm 11$ & $74 \pm 9^{a}$ & $74 \pm 7 c$ & $.0001^{\mathrm{a}}$ \\
\hline & & & & $.0001^{\mathrm{c}}$ \\
\hline \multicolumn{5}{|l|}{ PSET (sec) } \\
\hline \multirow[t]{3}{*}{ Left } & $7.98 \pm 5.7$ & $12.01 \pm 11.5$ & $14.95 \pm 13.97$ & .020 \\
\hline & & & & .022 \\
\hline & & & & .018 \\
\hline \multirow[t]{3}{*}{ Right } & $9.53 \pm 10.72$ & $14.0 \pm 14.35$ & $16.55 \pm 15.18^{c}$ & .023 \\
\hline & & & & .069 \\
\hline & & & & $.014^{c}$ \\
\hline \multirow[t]{3}{*}{ Yardage (yd) } & $6903 \pm 572$ & $7462 \pm 1029 a$ & $6412 \pm 991^{b, c}$ & $.001^{\mathrm{a}}$ \\
\hline & & & & $.0001^{\mathrm{b}}$ \\
\hline & & & & $.02^{\mathrm{c}}$ \\
\hline
\end{tabular}

a Significant change between T1 and T2 $(\mathrm{P}<.017)$

bSignificant change between T2 and T3 $(\mathrm{P}<.017)$

cSignificant change between T1 and T3 $(\mathrm{P}<.017)$

Tendon banding frequency, the frequency of collagen fibers, did not change over time (Table 4). 
Table 4.

Banding frequency (peak. / mm) of supraspinatus tendon at beginning (T1), middle (T2) and near end (T3) of competitive collegiate swimming season

\begin{tabular}{ccccc}
\hline Arm & T1 & T2 & T3 & P values \\
\hline Left & $1.58 \pm 0.12$ & $1.59 \pm 0.14$ & $1.54 \pm 0.13$ & 0.4 \\
Right & $1.55 \pm 0.15$ & $1.55 \pm 0.11$ & $1.54 \pm 0.15$ & 0.9 \\
\hline
\end{tabular}

\section{Discussion}

It was hypothesized that swimming pain and disability levels would increase with increased training volume (yardage), as training volume has been associated with increase pain and tendon pathology. ${ }^{5,6,7}$ However, despite a drastic volume increase from T1 to T3 and a volume drop-off from T2 to T3, no changes in pain were observed throughout the season. No changes in disability were observed between T1 and T2 as well as between T2 and T3, but a significant decrease in disability was observed between T1 and T3. This result may be due to favorable training conditions and fatigue management tactics employed throughout the season such as dryland training (training done out of water) and hypoalgesic (pain-relieving) effects. ${ }^{8}$

A reduction in ROM, specifically IR and HADD, was observed throughout the season. In other overhead sports, such as baseball, a loss of IR $\geq 25$ degrees is associated with a $450 \%$ increase in injury risk. ${ }^{9}$ Because of this, an increase in pain and disability would be expected with the observed loss of ROM; however, this did not occur. Therefore, it is possibly that IR and/or HADD ROM loss may be a healthy adaptation for our swimmers. Large amounts of IR during the pull phase and late initiation of ER during the recovery phase have been associated with a high risk of shoulder impingement (tendon or bursa rubbing against the acromion). ${ }^{10}$ Therefore, the relationship between pain, disability, and range of motion may suggest that a reduction of IR, as seen in these swimmers, could protect the swimmers' shoulder by limiting impingement through the pull and recovery phases. However, further investigation is required to confirm.

Posterior shoulder endurance increased throughout the season in both arms. Matthews et al ${ }^{11}$ have shown greater strength and endurance development of the internal rotator muscles, as opposed to the external rotator muscles, during the competitive swim season due to freestyle stroke mechanics. To combat this imbalance, a dryland strength training program is recommended to facilitate improvements in external rotator muscle endurance. Increased posterior shoulder endurance may have a protective effect on shoulder pain since rotator cuff fatigue has been found to cause potential subacromial impingement. ${ }^{12,13}$

No significant differences were observed in supraspinatus tendon organization. A previous study used similar methods to quantify tendon organization between a group of people with subacromial pain syndrome and a control group. ${ }^{14}$ No differences in supraspinatus tendon organization were observed. With no changes in pain and a decrease in disability throughout the season, since tendon organization would likely not have adapted without an increase in pain or disability. Research assessing tendon organization in other populations is currently being conducted. 


\section{Conclusion/Clinical Relevance}

Despite an increase in yardage, there was no increase in pain or disability as expected due to increased training load. Increases in posterior shoulder endurance may have mitigated muscular imbalances between the internal and external rotator muscles. A loss of IR is associated with increased injury risk in other overhead sports, but this may not be the case with swimming due to a decrease of impingement during the pull phase. No changes in supraspinatus tendon organization were observed possibly due to there being no changes in pain and a decrease in disability. Further research is required to understand the relationship between training volume, tendon organization, and disability.

\section{Disclosures and Conflicts of Interest}

The authors report no conflicts of interest. The abstract has been presented at the following conferences: American Physical Therapy Association (CSM) Podium Presentation, American Society of Shoulder and Elbow Therapists, Temple Symposium for Undergraduate Research and Creativity, Temple University College of Public Health Research Day, American Society of Biomechanics East Coast Meeting, Penn Center for Musculoskeletal Disorders Symposium.

\section{References}

1. Bak K. The practical management of swimmer's painful shoulder: etiology, diagnosis, and treatment. Clinical journal of sport medicine: official journal of the Canadian Academy of Sport Medicine 2010;20:386-390. 10.1097/JSM.0b013e3181f205fa

2. Wymore L, Fronek J. Shoulder functional performance status of National Collegiate Athletic Association swimmers: baseline Kerlan-Jobe Orthopedic Clinic scores. Am J Sports Med 2015;43:1513-1517. 10.1177/0363546515574058

3. Beach ML, Whitney, SL, Dickoff-Hoffman S. Relationship of shoulder flexibility, strength, and endurance to shoulder pain in competitive swimmers. J Orthop Sports Phys Ther 2010;16:262-268.

4. Harrington S, Meisel C, Tate A. A cross-sectional study examining shoulder pain and disability in Division I female swimmers. J Sport Rehabil 2014;23:65-75. $10.1123 /$ jsr.2012-0123

5. Tate A, Turner GN, Knab SE, Jorgensen C, Strittmatter A, Michener LA. Risk factors associated with shoulder pain and disability across the lifespan of competitive swimmers. J Athl Train 2012;47:149-158.

6. Hibberd EE, Myers JB. Practice habits and attitudes and behaviors concerning shoulder pain in high school competitive club swimmers. Clinical journal of sport medicine : official journal of the Canadian Academy of Sport Medicine 2013;23:450-455. 10.1097/JSM.0b013e31829aa8ff

7. Sein ML, Walton J, Linklater J, et al. Shoulder pain in elite swimmers: primarily due to swim-volume-induced supraspinatus tendinopathy. Br J Sports Med 2010;44:105-113. 
8. Naugle KM, Fillingim RB, Riley JL, 3rd. A meta-analytic review of the hypoalgesic effects of exercise. The journal of pain : official journal of the American Pain Society 2012;13:1139-1150. 10.1016/j.jpain.2012.09.006

9. Shanley E, Rauh MJ, Michener LA, Ellenbecker TS, Garrison JC, Thigpen CA. Shoulder range of motion measures as risk factors for shoulder and elbow injuries in high school softball and baseball players. Am J Sports Med 2011;39:1997-2006. $10.1177 / 0363546511408876$

10. Yanai T, Hay JG. Shoulder impingement in front-crawl swimming: II. Analysis of stroking technique. Med Sci Sports Exerc 2000;32:30-40.

11. Matthews MJ, Green D, Matthews H, Swanwick E. The effects of swimming fatigue on shoulder strength, range of motion, joint control, and performance in swimmers. Phys Ther Sport 2017;23:118-122. 10.1016/j.ptsp.2016.08.011

12. Chopp-Hurley JN, O'Neill JM, McDonald AC, Maciukiewicz JM, Dickerson CR. Fatigue-induced glenohumeral and scapulothoracic kinematic variability: Implications for subacromial space reduction. J Electromyogr Kinesiol 2016;29:55-63. 10.1016/j.jelekin.2015.08.001

13. Chopp JN, O'Neill JM, Hurley K, Dickerson CR. Superior humeral head migration occurs after a protocol designed to fatigue the rotator cuff: a radiographic analysis. J Shoulder Elbow Surg 2010;19:1137-1144. 10.1016/j.jse.2010.03.017

14. Pozzi F, Seitz AL, Plummer HA, Chow K, Bashford GR, Michener LA. Supraspinatus tendon micromorphology in individuals with subacromial pain syndrome. J Hand Ther 2017;30:214-220. 10.1016/j.jht.2017.04.001

\section{Statement of Contributions}

Angela Tate, Stephen Thomas and Thomas Joseph Sarver were responsible for study design. Angela Tate, Stephen Thomas, Laura DiPaola, Jeffrey Yim and Joseph Sarver were responsible for data collection. Laura DiPaola, Jeffrey Yim and Ryan Paul were responsible for data analysis. Ryan Paul was responsible for preparation of this document. 